Article

\title{
Development of Magnetic Multi-Shelled Hollow Catalyst for Biodiesel Production
}

\author{
Liang Zhou ${ }^{1,2}$, Jingang Yao ${ }^{1,2}$, Zhaoxia Ren ${ }^{1,2}$, Zhenqiang Yu ${ }^{1,2}$ and Hongzhen Cai $1,2, *$ \\ 1 School of Agricultural Engineering and Food Science, Shandong University of Technology, \\ Zibo 255049, China; zhouliang199610@163.com (L.Z.); yaojingang@sdut.edu.cn (J.Y.); \\ renzhaoxia527@163.com (Z.R.); sdbxyzq@163.com (Z.Y.) \\ 2 Shandong Research Center of Engineering and Technology for Clean Energy, Zibo 255049, China \\ * Correspondence: chzh666666@126.com
}

Received: 21 April 2020; Accepted: 15 May 2020; Published: 1 June 2020

check for updates

\begin{abstract}
The magnetic CaO-based catalyst has endorsed great enhancements in biodiesel synthesis. In the present work, novel multi-shelled hollow $\gamma-\mathrm{Fe}_{2} \mathrm{O}_{3}$ stabilized $\mathrm{CaO}$ microspheres were synthesized using a facile one-step hydrothermal method. The strategy revealed that the well-defined multi-shelled hollow structures were formed with magnetism; the presence of $\gamma-\mathrm{Fe}_{2} \mathrm{O}_{3}$ was the key for the effective structural stabilization, and the multi-shelled hollow structures provided the sites for the active material. The synthesized catalyst was employed for the preparation of biodiesel by transesterification of palm oil and methanol. A four factors response surface methodology was adopted for optimizing the reaction conditions. Ca80Fe20 with a yield of $96.12 \%$ performed the highest catalytic activity under reaction conditions of $2 \mathrm{~h}$, a methanol to oil ratio of $12: 1,65^{\circ} \mathrm{C}$ and $11 \mathrm{wt} . \%$ of catalyst dosage. The catalyst under the optimum transesterification conditions also performed a better recyclability $(>85 \%)$. In addition, the response surface methodology (RSM) based on the Box-Behnken design was used to optimize the four reaction parameters.
\end{abstract}

Keywords: biodiesel; transesterification; multi-shelled hollow; $\mathrm{CaO} ; \gamma-\mathrm{Fe}_{2} \mathrm{O}_{3} ; \mathrm{RSM}$

\section{Introduction}

Fossil fuels are the most commonly used energy sources, accounting for $80 \%$ of the world's energy demand. However, with the massive depletion of fossil fuel increased, the search for alternative energy sources has become a tremendous source of attention for the world [1]. Several studies have shown that biodiesel could be the greatest potential alternative fuel in the near future [2-5].

Biodiesel, also called Fatty Acid Methyl Esters (FAME), is obtained from the transesterification reaction of renewable lipids (vegetable oils and animal fats) with methanol in the presence of an applicable catalyst [6]. Compared with fossil fuels, biodiesel is free from sulfur and has a higher flash point $[7,8]$. Moreover, the application of biodiesel in diesel engines has shown good performance and reduced greenhouse gas emission to a great extent $[9,10]$.

Biodiesel is mostly synthesized through a transesterification reaction by using homogeneous or heterogeneous catalysts [11]. The transesterification reaction with a homogeneous catalyst is the most common and commercial technique due to the fact that the by-product glycerol can be reused in the reforming reaction of hydrogen production. Unfortunately, homogeneous catalysts suffer from environmental pollution and high costs of recycling [12]. These issues are addressed by the use of heterogeneous catalysts since they can be easy to separate and recycle [13].

As a typical heterogeneous catalyst, calcium oxide $(\mathrm{CaO})$ has shown tremendous potentials in the biodiesel production due to its strong basic strength and wide source [14,15]. It can be obtained from extensive natural resources, such as egg shell, abalone shell, oyster shell and mud clamshell [16]. 
Banković et al. [15] summarized that there were numerous CaO-based catalysts that have been widely used in the transesterification reaction. They found that the determinants of the performance of the catalyst are the alkalinity, specific surface area and activity. Toledo et al. [17] created a fancy one-step synthesis of the $\mathrm{CaO}-\mathrm{ZnO}$ catalyst for the transesterification reaction. The activity of the catalyst was shown when the yield dropped to $64 \%$ after the second cycle. Additionally, Chen et al. [18] performed the production of biodiesel over the ethanol-modified $\mathrm{CaO}(\mathrm{M}-\mathrm{CaO})$ catalyst. The maximal yield was reached at $96.2 \%$ with methanol, and the recyclability of the $\mathrm{M}-\mathrm{CaO}$ catalyst was superior than the unmodified $\mathrm{CaO}$ catalyst after ten cycles. However, the drawback of using CaO-based catalysts is the difficulty of separation and recovery.

Since researchers are concerned about the sustainability of the process, the recovery, reuse and reactivation of the catalyst, and the substitution of the CaO-based catalysts by the ferromagnetic CaO-based catalysts, has gained larger consideration. Liu et al. [19] synthesized the magnetic nanoparticle $\mathrm{MgFe}_{2} \mathrm{O}_{4} @ \mathrm{CaO}$ via alkali precipitation. The $\mathrm{CaO}$-coated magnetic catalyst had a great stability and recyclability due to the synergy between Ca ions and Mg ions. Ezzah-Mahmudah et al. [20] investigates the characterization of the $\mathrm{Fe}_{2} \mathrm{O}_{3} / \mathrm{CaO}$ catalyst in biodiesel production. The addition of $\mathrm{Fe}_{2} \mathrm{O}_{3}$ on the $\mathrm{CaO}$ catalyst not only improved the catalytic activity but also had a significant positive effect, which is consistent with the research results of Shi et al. [21]. Ca ions and Fe ions changed the surface characteristics of the catalyst, and the stability of the system was improved. More importantly, these catalysts exhibit low activities. Thus, the development of ideal ferromagnetic CaO-based catalysts is a significant challenge.

Until now, the application of magnetic core-shell catalysts in biodiesel synthesis has been a hot topic owing to the easy separation of magnetic catalysts from the reaction system and the large number of functional groups existing on the outer shells [22]. Xie et al. [23] successfully prepared the core-shell $\mathrm{Fe}_{3} \mathrm{O}_{4} / \mathrm{SiO}_{2}$ carrier with good magnetism. After immobilizing polymeric acidic ionic liquid on the magnetic carrier, it exhibited good performance in the synthesis of biodiesel. However, as of now, the morphologies of all reported magnetic materials for biodiesel production were simple (solid sphere or simple hollow sphere), and the synthesis process of magnetic materials was complex.

Therefore, we attempted to use palm oil for biodiesel production via the magnetic catalyst and used the response surface methodology (RSM) based on the Box-Behnken design to optimize the reaction parameters. In this work, an easy one-step hydrothermal synthesis of a magnetic catalyst, $\gamma-\mathrm{Fe}_{2} \mathrm{O}_{3}$ stabilized $\mathrm{CaO}$ microspheres featuring multi-shelled morphologies, was shown. The prepared catalyst was characterized by various techniques such as STEM-EDS, XRD, ICP-OES, BET, $\mathrm{CO}_{2}-\mathrm{TPD}$, FT-IR and VSM. Then, the influence parameters of the transesterification reaction (reaction time, the molar ratio of methanol to oil, reaction temperature and catalyst dosage) were also investigated.

\section{Materials and Methods}

\subsection{Materials}

Palm oil was sourced from Baolin Natural (Jiangxi, China), D-(+)-Xylose, Urea, Glycine, Dimethyl carbonate, Ethanol anhydrous, Methanol anhydrous, Calcium nitrate tetrahydrate $\left(\mathrm{Ca}\left(\mathrm{NO}_{3}\right)_{2} 4 \mathrm{H}_{2} \mathrm{O}\right)$ and Iron nitrate nonahydrate $\left(\mathrm{Fe}\left(\mathrm{NO}_{3}\right)_{2} 9 \mathrm{H}_{2} \mathrm{O}\right)$ were all purchased from Da Mao Chemical Factory (Tianjin, China). All reagents were analytical grade and used without further purification.

\subsection{Catalyst Preparation}

The synthetic method of the catalysts was template-assisted hydrothermal. As illustrated in Figure 1, a mixture of D-(+)-xylose $(40 \mathrm{mmol})$ and glycine $(6.6 \mathrm{mmol})$ was dissolved in deionized water $(30 \mathrm{~mL})$ and stirred vigorously for $10 \mathrm{~min}$. After that, $\mathrm{Ca}\left(\mathrm{NO}_{3}\right)_{2} 4 \mathrm{H}_{2} \mathrm{O}$ and $\mathrm{Fe}\left(\mathrm{NO}_{3}\right)_{2} 9 \mathrm{H}_{2} \mathrm{O}$ with different concentrations (a total of $17 \mathrm{mmol}, \mathrm{Ca}^{2+}: \mathrm{Fe}^{2+}=90: 10,85: 15,80: 20,75: 25$ ) were added in the mixture solution. Thereafter, $2 \mathrm{M}$ urea solution $(6 \mathrm{ml})$ was added drop by drop into the reaction mixture, and the resulting solution was sealed into a Teflon reactor and reacted at $180^{\circ} \mathrm{C}$ for $2 \mathrm{~h}$ by 
microwave hydrothermal method. The obtained black powders were washed with deionized water and anhydrous ethanol alternatively and dried at $80^{\circ} \mathrm{C}$ for $12 \mathrm{~h}$. After that, the resulting catalysts were calcined at $800^{\circ} \mathrm{C}$ for $2 \mathrm{~h}$ with a heating rate of $5^{\circ} \mathrm{C} \mathrm{min}-1$ in air. For convenience, the following nomenclature is similar to the previous report [24].

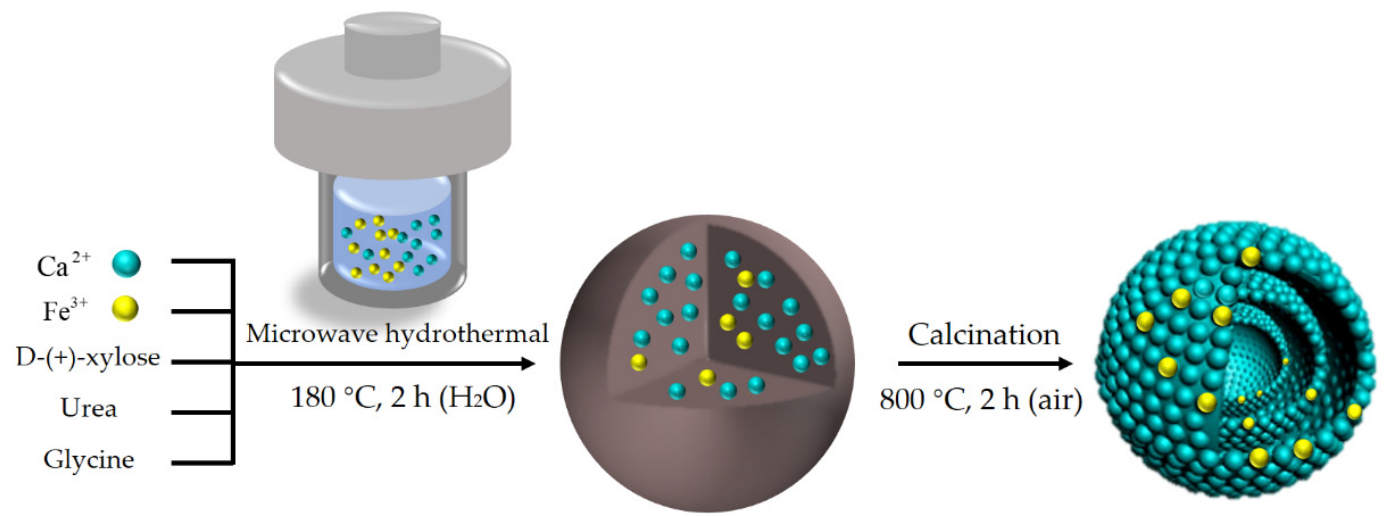

Figure 1. Preparation process of the catalyst.

\subsection{Characterization of Catalyst}

The microstructure of the catalyst was probed by TEM (Tecnai $G^{2}$ Spirit, FEI, Hillsboro, OR, USA) equipped with an energy dispersive spectrometer (EDS). The powders were dispersed onto $\mathrm{Cu}$ grids equipped with a carbon membrane. XRD (Bruker AXS D8 Advance, Karlsruhe, Germany) was used to analyze the crystalline structure of catalysts, and inductively coupled plasma-atomic emission spectrometry (ICP-AES) was analyzed on Agilent 725 ES. $\mathrm{N}_{2}$ adsorption desorption and the surface area of the catalysts were examined with a BET surface area analyzer (ASAP 2460, Micromeritics, Norcross, GA, USA). The basic properties were studied by $\mathrm{CO}_{2}$-TPD (AutoChem II 2920, Micromeritics, Norcross, GA, USA). The FT-IR spectra used the KBr method in the wavelength region of $4000-400 \mathrm{~cm}^{-1}$ (Nicolet 5700, Thermo-Fisher Nicolet, Waltham, MA, USA). The magnetic hysteresis loops of the catalysts were measured using a vibrating sample magnetometer (Versalab, Quantum Design, San Diego, CA, USA).

\subsection{Transesterification Procedure}

The transesterifications of palm oil were conducted in a round bottom flask with a magnetic stirrer and sealing reflux condenser. In order to select the best catalyst, the fatty acid methyl ester production using different catalysts was done under the same reaction conditions. Furthermore, the influence of parameters such as the reaction time (1-3 h), the molar ratio of methanol to oil (from 3:1 to 15:1), the reaction temperature $\left(50-70{ }^{\circ} \mathrm{C}\right)$ and the catalyst dosage $(5-13 \mathrm{wt} . \%)$ on the fatty acid methyl ester production was investigated.

Then, the cooled sample was collected from the upper layer by centrifugation (12,000 rpm, $10 \mathrm{~min})$. After removing redundant methanol by reduced pressure distillation (STRIKE300, CHEMTRON, Germany), the biodiesel was finally obtained.

The biodiesel was analyzed by a GC-MS system (Agilent, 6890-5973N) with agilent DB-1701 capillary column dimensions $60 \mathrm{~m}, 0.25 \mathrm{~mm}, 0.25 \mathrm{~mm}$. The injector temperature was $280{ }^{\circ} \mathrm{C}$. The temperature of GC was $40{ }^{\circ} \mathrm{C}$ and was raised at a ramp of $5{ }^{\circ} \mathrm{C} / \mathrm{min}$ to $240{ }^{\circ} \mathrm{C}$, and then it was held for $5 \mathrm{~min}$. $5 \mathrm{ml}$ of sample was dissolved in dimethyl carbonate as an internal standard, and $1 \mu \mathrm{L}$ of this mixture was injected in the column $[10,17]$. The FAME content was calculated by the given formula [25]:

$$
\operatorname{FAME}(\%)=\frac{\sum \mathrm{A}-\mathrm{AIS}}{\mathrm{AIS}} \times \frac{\mathrm{WIS}}{\mathrm{M}} \times 100
$$


where $\sum \mathrm{A}$ is the area of all peaks in the chromatogram (C6-C24:1), AIS is the area of the internal standard (dimethyl carbonate, DMC), WIS is the weight of the internal standard (g), and M is the weight of the biodiesel sample (g).

\subsection{Catalyst Reusability}

To investigate the reusability of the catalyst, the optimal catalyst was recycled after the transesterification reaction by a powerful magnet and washed with anhydrous methanol. Then, the recycled catalyst was dried overnight at $80^{\circ} \mathrm{C}$ and was used for five cycles under the optimal reaction conditions.

\subsection{Response Surface Methodology (RSM) Optimization}

RSM is a mathematical and statistical technique that can optimize the conversion of FAME by using Design-Expert software version 8.0.6. The independent variables, i.e., reaction temperature (A), reaction time (B), dosage of catalyst (C) and the molar ratio of methanol to oil (D), were used to maximize the FAME conversion (F). Table 1 shows the levels of the independent variables. Using a second-order polynomial equation to analyze the experimental data through response surface regression. The regression analysis, analysis of variance (ANOVA) and contour plot were plotted to find the optimum conditions for the yield of FAME.

$$
Y=\beta_{0}+\sum_{\mathrm{i}=1}^{4} \beta_{\mathrm{i}} \alpha_{\mathrm{i}}+\sum_{\mathrm{i}=1}^{4} \beta_{\mathrm{ii}} \alpha_{\mathrm{i}}^{2}+\sum_{\mathrm{i}<\mathrm{j}=1}^{4} \beta_{\mathrm{ii}} \alpha_{\mathrm{i}} \alpha_{\mathrm{j}}
$$

where $Y$ is the response (predicted biodiesel yield), $\beta_{0}$ is the intercept, $\alpha_{i}$ and $\alpha_{j}$ are the factors, and $\beta_{i}$ and $\beta_{\mathrm{ii}}$ are the model coefficients [25].

Table 1. Box-Behnken independent variables (coded and uncoded).

\begin{tabular}{cccc}
\hline Factors & \multicolumn{3}{c}{ Levels } \\
\cline { 2 - 4 } & $\mathbf{- 1}$ & $\mathbf{0}$ & $\mathbf{1}$ \\
\hline Reaction temperature $\left({ }^{\circ} \mathrm{C}\right)$ & 50 & 60 & 70 \\
Reaction time $(\mathrm{h})$ & 1 & 2 & 3 \\
Dosage of catalyst $(\mathrm{wt} . \%)$ & 5 & 9 & 13 \\
Methanol: oil molar ratio $(\mathrm{mol} / \mathrm{mol})$ & 3 & 9 & 15 \\
\hline
\end{tabular}

\section{Results}

\subsection{Analysis of Catalyst}

\subsubsection{Structure and Composition of the Catalyst}

The electron microscopy graphs of the obtained materials, shown in Figure 2, indicated that hollow microspheres composed of porous shells were successfully obtained by the microwave hydrothermal method. As shown in Figure 2b, it is evident that the catalysts with different molar ratios of $\mathrm{Ca}^{2+}$ to $\mathrm{Fe}^{3+}$ ions have an impact on the shell-comprising Cao nanoparticles, the shells of Ca90Fe10 were fuzzy and the shell of catalysts become more porous and complete as the $\mathrm{Fe}^{3+}$ ions increase. In particular, $\mathrm{Ca} 80 \mathrm{Fe} 20$ shows the most clearly hierarchical multilayered shelled microsphere structure in Figure 2a,e and Figure 3c. However, with the increase of $\mathrm{Fe}^{3+}$ ions addition, some hollow microspheres were broken into pieces (Figure $2 \mathrm{~b}, \mathrm{f}$ ), meaning that superfluous $\mathrm{Fe}^{3+}$ ions can lead to structural instability. The catalyst with a multilayered shelled structure shows a good performance in the transesterification reaction, which could result from the high surface area and pore volume. 


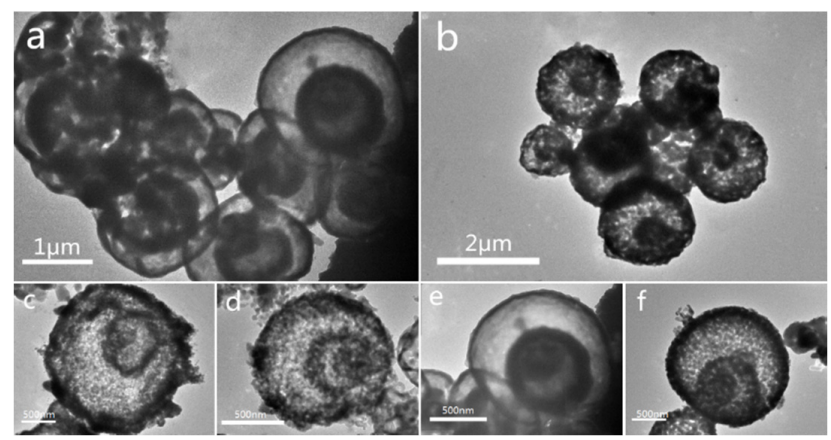

Figure 2. TEM images of hollow microsphere with different $\mathrm{Ca} / \mathrm{Fe}$ molar ratio. (a,e) Ca80Fe20, (b,f) Ca75Fe25, (c) Ca90Fe10, (d) Ca85Fe15.

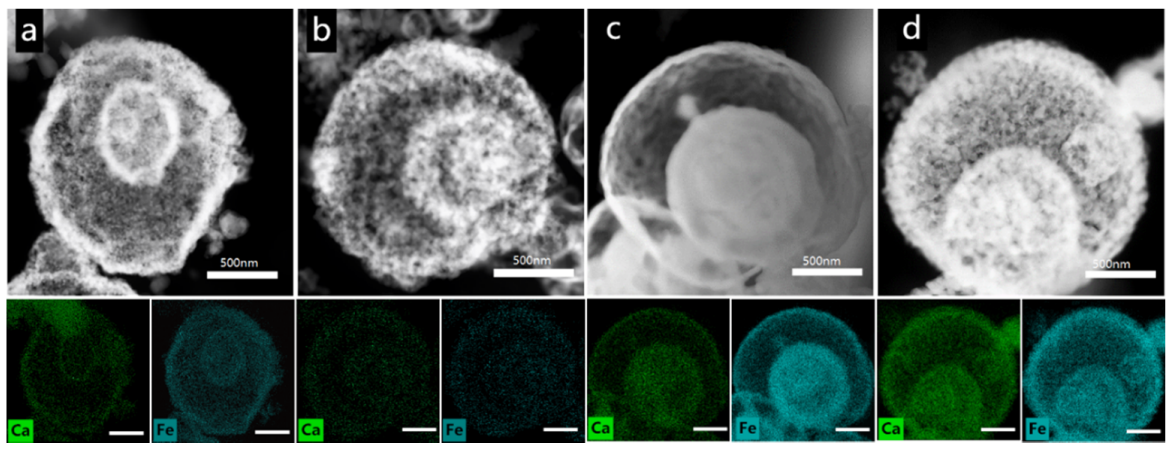

Figure 3. HAADF-STEM images of (a) Ca90Fe10, (b) Ca85Fe15, (c) Ca80Fe20 and (d) Ca75Fe25 along with EDS elemental mapping.

The HAADF-STEM images complemented by EDS maps clearly reveal, in Figure 3, that the active components and the magnetic fraction form the homogeneous mixing structure. The $\gamma-\mathrm{Fe}_{2} \mathrm{O}_{3}$ as a barrier can effectively prevent the aggregation of the $\mathrm{CaO} / \mathrm{CaCO}_{3}$ particles, which is beneficial for the transesterification reaction [26].

\subsubsection{X-ray Diffraction Analysis}

XRD patterns, as shown in Figure 4, indicated that after calcining the catalyst, the materials were composed of Cao and $\gamma-\mathrm{Fe}_{2} \mathrm{O}_{3}$ primarily. As can be seen, according to PDF 77-2376 and PDF 86-2342 respectively, $\mathrm{CaO}(2 \theta=32.221,37.376,53.890,64.193,67.418)$ and $\mathrm{CaCO}_{3}(2 \theta=29.087,46.600)$ are observed, and it is confirmed that the catalysts were calcined at $800{ }^{\circ} \mathrm{C}$. The presence of $\mathrm{CaCO}_{3}$ is due to $\mathrm{CO}_{2}$ being released by the thermal decomposition of the carbon templates reacted with $\mathrm{Ca}(\mathrm{OH})_{2}$. Besides, the formation of $\mathrm{Ca}(\mathrm{OH})_{2}$ is due to the water in the atmosphere absorption of $\mathrm{CaO}$ [26].

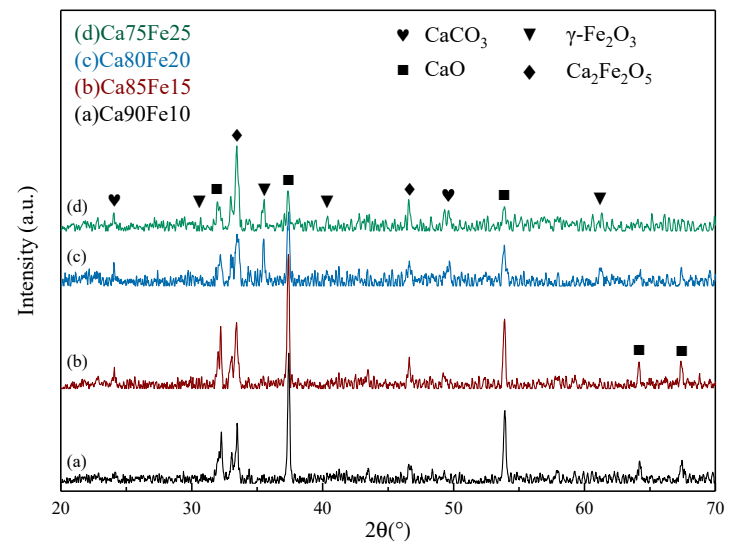

Figure 4. XRD patterns of the catalysts. 
As can be seen, the intensity of the magnetic $\gamma-\mathrm{Fe}_{2} \mathrm{O}_{3}$ characteristic peaks (PDF 25-1402) becomes stronger, with the increase of $\mathrm{Fe}^{3+}$ ions. What is more, the $\mathrm{Ca}_{2} \mathrm{Fe}_{2} \mathrm{O}_{5}$ appears as the signal of the $\gamma-\mathrm{Fe}_{2} \mathrm{O}_{3}$ crystal is weakened, which indicates that few active $\mathrm{Ca}_{2} \mathrm{Fe}_{2} \mathrm{O}_{5}$ components were formed successfully [27].

\subsubsection{BET Analysis}

Table 2 lists the BET surface area and pore volume parameters of the samples. The greater the active surface area and pore volume of the samples, the better the contact with the palm oil. As illustrated, the surface area of the sample increases (from 38.8 to $72.2 \mathrm{~m}^{2} \mathrm{~g}^{-1}$ ) as $\mathrm{Fe}^{3+}$ ions increase (from $10 \%$ to $20 \%$ ). However, it is also observed that the surface area of Ca75Fe25 decreases significantly to $9.6 \mathrm{~m}^{2} \mathrm{~g}^{-1}$ as $\mathrm{Fe}^{3+}$ ions reach $25 \%$. The sharp decline may be due to the formation of superfluous $\mathrm{Ca}_{2} \mathrm{Fe}_{2} \mathrm{O}_{5}$ and the decrease of the crystallite size [28].

Table 2. Summary of the prepared catalysts.

\begin{tabular}{|c|c|c|c|c|c|}
\hline Sample & $\begin{array}{c}\text { Ca:Fe } \\
\text { (Molar Ratio) }^{1}\end{array}$ & $\begin{array}{l}\text { Crystallite } \\
\text { Size }(\mathrm{nm})^{2}\end{array}$ & $\begin{array}{c}\text { Surface Area } \\
\left(\mathrm{m}^{2} / \mathrm{g}\right)\end{array}$ & $\begin{array}{c}\text { Average Pore } \\
\text { volume }\left(\mathrm{cm}^{3} / \mathrm{g}\right)\end{array}$ & $\begin{array}{l}\text { Average Pore } \\
\text { Diameter (£) }\end{array}$ \\
\hline Ca90Fe10 & $8.8: 1.0$ & 42.1 & 38.8 & 0.24 & 24.5 \\
\hline Ca85Fe15 & $8.5: 1.6$ & 48.0 & 43.3 & 0.44 & 75.8 \\
\hline Ca80Fe20 & 8.1:2.0 & 50.8 & 72.2 & 0.25 & 17.3 \\
\hline Ca75Fe25 & 7.2:2.7 & 26.1 & 9.6 & 0.01 & 5.2 \\
\hline
\end{tabular}

${ }^{1}$ determined by ICP-OES. ${ }^{2}$ Calculated by the Debye-Scherrer's Equation using the XRD data of catalysts.

\subsubsection{The $\mathrm{CO}_{2}-\mathrm{TPD}$ Analysis}

The $\mathrm{CO}_{2}-\mathrm{TPD}$ experiments were conducted, and the results are shown in Figure 5. It can be observed that all catalysts showed only one peak between $550{ }^{\circ} \mathrm{C}$ and $700{ }^{\circ} \mathrm{C}$; this phenomenon is in agreement with the study from Liu [19]. The desorption peaks of Ca90Fe10, Ca85Fe15 and Ca80Fe20 are at $572{ }^{\circ} \mathrm{C}, 627^{\circ} \mathrm{C}$ and $661{ }^{\circ} \mathrm{C}$ respectively, which corresponds to the strong basic sites of $\mathrm{CaO}$ and $\mathrm{Ca}_{2} \mathrm{Fe}_{2} \mathrm{O}_{5}$. On the basis of the value obtained from the integration of the total peak areas, one sees that the basicity of the catalyst increases with the increase of $\mathrm{Fe}^{3+}$ ions, i.e., $0.15,0.13$ and $0.35 \mathrm{mmol}$ $\mathrm{CO}_{2} / \mathrm{g}$-catalyst for catalysts with 10,15 and $20 \mathrm{wt} . \% \mathrm{Fe}^{3+}$ ions, respectively. However, when $\mathrm{Fe}^{3+}$ ions reach $25 \%$, the desorption peaks and the peak areas sharply decrease to $589^{\circ} \mathrm{C}$ and $0.17 \mathrm{mmol}$ $\mathrm{CO}_{2} /$ g-catalyst. This can be correlated with the BET analysis as excess $\gamma-\mathrm{Fe}_{2} \mathrm{O}_{3}$ phases have the lowest surface areas since the fewest active sites are in Ca80Fe20.

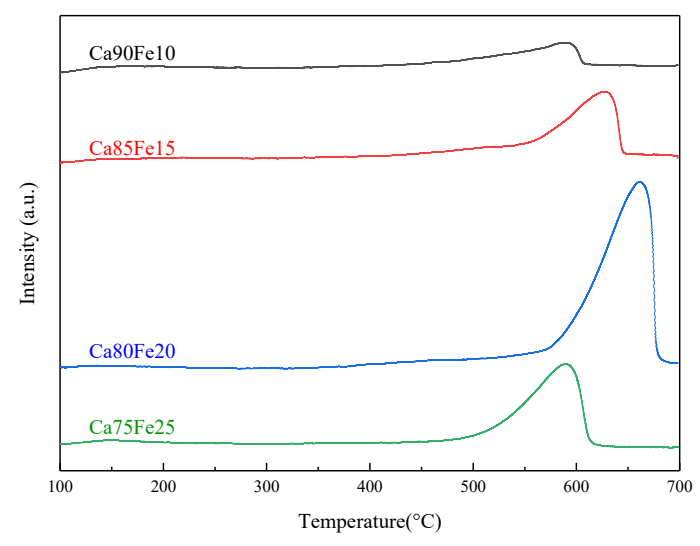

Figure 5. $\mathrm{CO}_{2}-\mathrm{TPD}$ curves of the catalysts. 


\subsubsection{FT-IR Analysis}

The FT-IR spectra of all catalysts by using transmission absorption technique in the range $4000-400 \mathrm{~cm}^{-1}$ were presented in Figure 6, All the FT-IR curves shown in Figure 6 have the similar sharp absorption bands, and six characteristic absorption bands could be observed at 3644, 3430, 1530, 1413, 873 and $713 \mathrm{~cm}^{-1}$ respectively. The absorption band at $713 \mathrm{~cm}^{-1}$ is the in-plane bending vibration mode of the $\mathrm{CO}_{3}^{2-}$ groups, and the out-of-plane bending vibration could be attributed to the absorption band present at $873 \mathrm{~cm}^{-1}$. Accordingly, the absorption band for $\mathrm{CO}_{3}^{2-}$ groups can be found at $1413 \mathrm{~cm}^{-1}$ (asymmetric stretching) [29]. It is noteworthy that the increase of $\mathrm{Fe}^{3+}$ ions weakens the in-plane bending vibration. Furthermore, the adsorption band at 607 and $442 \mathrm{~cm}^{-1}$ corresponds to the Fe-O stretching vibration modes of $\gamma-\mathrm{Fe}_{2} \mathrm{O}_{3}$ [30].

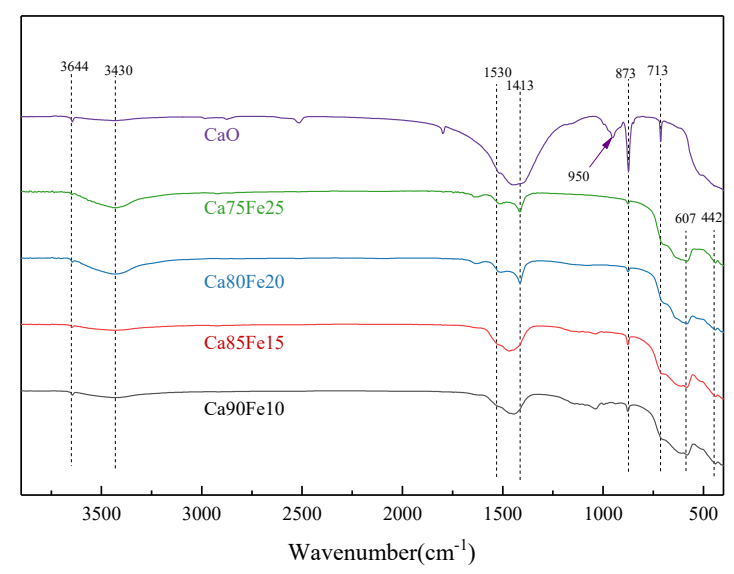

Figure 6. FT-IR spectrum of catalysts.

\subsection{Catalyst Performance}

\subsubsection{Catalyst Selection}

In order to select the best catalyst for the next run, a series of catalysts were performed in the transesterification of palm oil with methanol. In addition, the commercial Cao was also performed in comparison. As exhibited in Figure 7, the results display that the yield of biodiesel was $91.92 \%$, 91.88\%, 94.60\%, 95.73\% and 82.82\% for commercial Cao, Ca90Fe10, Ca85Fe15, Ca80Fe20 and Ca75Fe15. Ca80Fe20 exhibited the optimal performance (in the TEM, BET and $\mathrm{CO}_{2}-\mathrm{TPD}$ analysis), and the FAME yield can achieve $95.73 \%$ under the same reaction conditions. Thus, in this work, Ca80Fe20 can be considered a suitable catalyst and can then used for the next run.

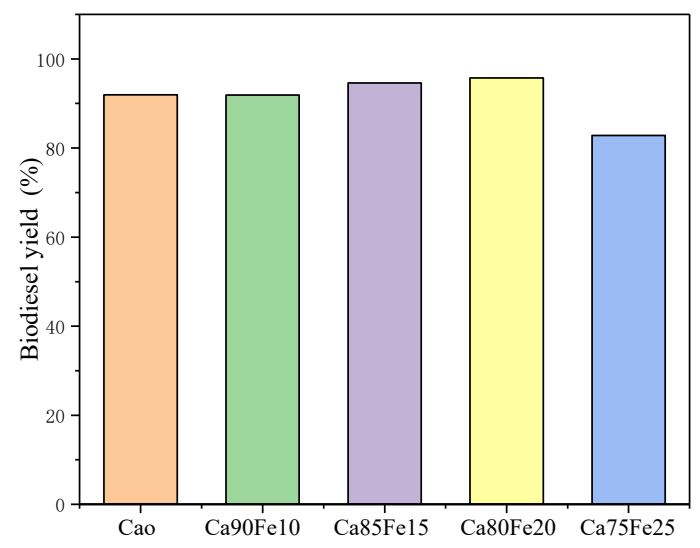

Figure 7. Comparison of the catalytic performance for pure Cao, Ca90Fe10, Ca85Fe15, Ca80Fe20 and Ca75Fe25 (reaction condition: catalyst dosage $11 \mathrm{wt} . \%$, methanol: oil ratio of $9: 1,65^{\circ} \mathrm{C}, 2 \mathrm{~h}$ ). 


\subsubsection{Effect of Reaction Time}

As illustrated in Figure 8a, the FAME yield rises with the reaction time, and the influence of the FAME yield was studied at different times from $1 \mathrm{~h}$ to $3 \mathrm{~h}$. The maximal FAME yield of Ca80Fe20 was $95.73 \%$ when the reaction time was up to $2 \mathrm{~h}$. The reaction time had no significant effect after $2 \mathrm{~h}$, which indicates that the FAME reached the distribution equilibrium [31]. However, the FAME yield decreased slightly as the reaction continued. This is due to the reverse reaction of transesterification (hydrolysis), which tends to produce more fatty acid to form soaps [32-34]. Thus, the optimum yield was obtained at $2 \mathrm{~h}$.
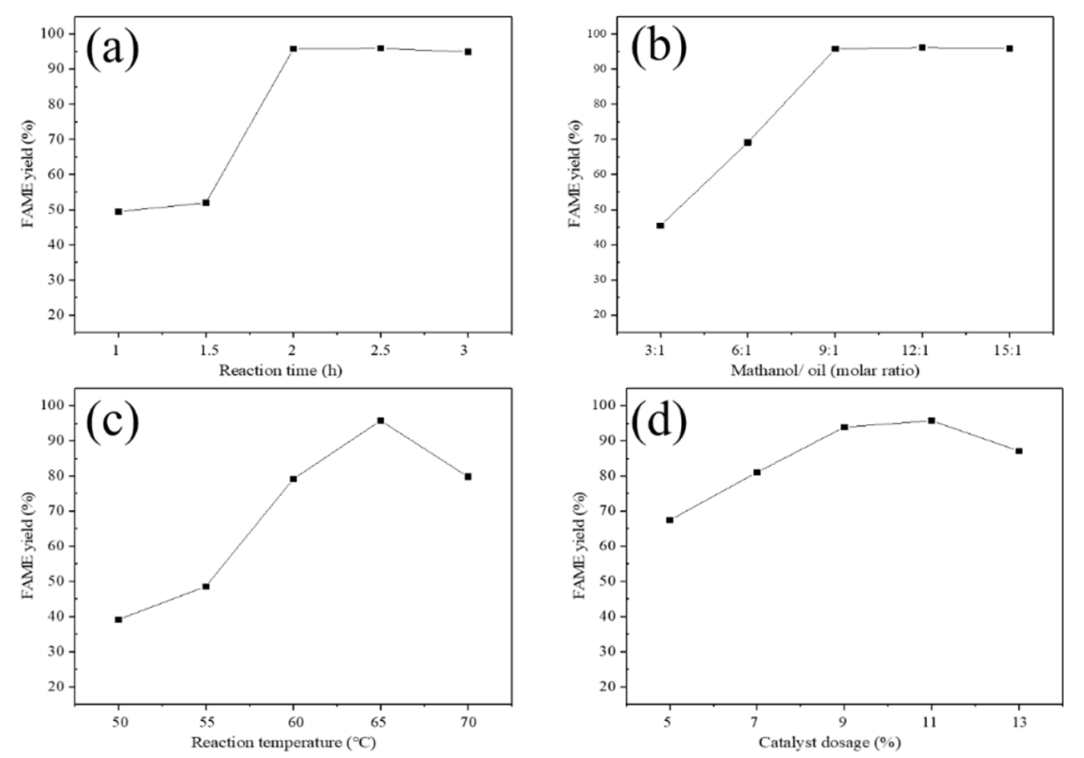

Figure 8. Effect of the different operating parameters; (a) Effect of the reaction time (reaction condition: catalyst dosage $11 \mathrm{wt} . \%$, methanol: oil ratio of 9:1, $65^{\circ} \mathrm{C}$ ); (b) Effect of the methanol molar ratio (reaction condition: catalyst dosage $11 \mathrm{wt} . \%, 65^{\circ} \mathrm{C}, 2 \mathrm{~h}$ ); (c) Effect of the reaction temperature (reaction condition: catalyst dosage 11 wt.\%, methanol: oil ratio of 9:1, 2 h); (d) Effect of the catalyst dosage (reaction condition: methanol: oil ratio of $9: 1,65^{\circ} \mathrm{C}, 2 \mathrm{~h}$ ).

\subsubsection{Effect of Methanol Molar Ratio}

The effect of the methanol molar ratio on the FAME yield is illustrated in Figure 8b; the methanol to oil molar ratio varied in the range of 3:1-15:1, and the FAME yield increased from $45.49 \%$ to $96.12 \%$ with an increase in the methanol to oil molar ratio from 3:1-12:1. This can be ascribed to the proper dose of methanol and to the transesterification reaction becoming dominant. However, the FAME yield decreased lightly in the methanol to oil molar ratio from 12:1-15:1, which is attributed to the residual glycerol in the biodiesel layer, which resulted in an equilibrium reaction, starting the backward reaction and again meeting with the methyl ester to form a monoglyceride [35]. In fact, excessive use of methanol has no substantial effect on biodiesel production, and excessive methanol can make it difficult to separate glycerol from the biodiesel phase [31]. Therefore, a molar ratio of 12:1 is the optimum ratio for the reaction.

\subsubsection{Effect of Reaction Temperature}

To investigate the effect of the temperature on the FAME yield, the transesterification reaction was performed at temperatures of $50{ }^{\circ} \mathrm{C}, 55^{\circ} \mathrm{C}, 60^{\circ} \mathrm{C}, 65^{\circ} \mathrm{C}$ and $70^{\circ} \mathrm{C}$ (Figure $8 \mathrm{c}$ ). The result showed that the reaction rate was accelerated at a higher temperature and that the highest FAME yield reached $95.73 \%$ at a temperature of $65^{\circ} \mathrm{C}$. However, higher temperatures showed a decrease in the yield of methyl esters, probably due to the evaporation of methanol [36]. 


\subsubsection{Effect of Catalyst Dosage}

The effect of the catalyst dosage as a process parameter for the production of methyl esters was also studied by varying the weight percentage of the catalyst from $5 \mathrm{wt} . \%$ to $13 \mathrm{wt} . \%$. It is clear from Figure $8 \mathrm{~d}$ that the FAME yield was low $(67.43 \%)$ at a catalyst dosage of $5 \mathrm{wt} . \%$ and gradually increased up to $11 \mathrm{wt} . \%$. The yield of the reaction decreased above a dosage of $11 \mathrm{wt} . \%(95.73 \%)$, probably due to the agglomeration of catalyst particles, and the poor diffusion of reactants and products [34].

\subsubsection{Reusability of Catalyst}

The recyclability of the sample is shown by VSM at room temperature in Figure 9a. One can observe that the saturation magnetization value of $\mathrm{Ca} 80 \mathrm{Fe} 20$ was $3.72 \mathrm{emu} / \mathrm{g}$. Hence, the simple method for recycling the catalyst from the mixture solution clearly confirmed that the catalysts can be adsorbed in the presence of a powerful magnet (Figure 9c). As shown in Figure 9b, the regenerated catalyst gave $>85 \%$ conversions of palm oil under the optimal conditions after five cycles. The FAME yield for the first and second runs were $96.12 \%$ and $95.34 \%$, respectively. These results demonstrated that Ca80Fe20 could preserve the desired high activity and that the superior stability of Ca80Fe20 during the reactions could improve the multiple reuse performance of biodiesel. Shi et al. [21] had reported the same observation, whereby the catalytic performance of $\gamma-\mathrm{Fe}_{2} \mathrm{O}_{3}$ doped calcium oxide composite catalysts in biodiesel production was reduced to $27.95 \%$ after the fourth operation, demonstrating their stable reusability. The decrease of the yield could be due to the adsorption of organic matters and the loss of basic sites on the catalyst surface during the reaction $[8,37]$.
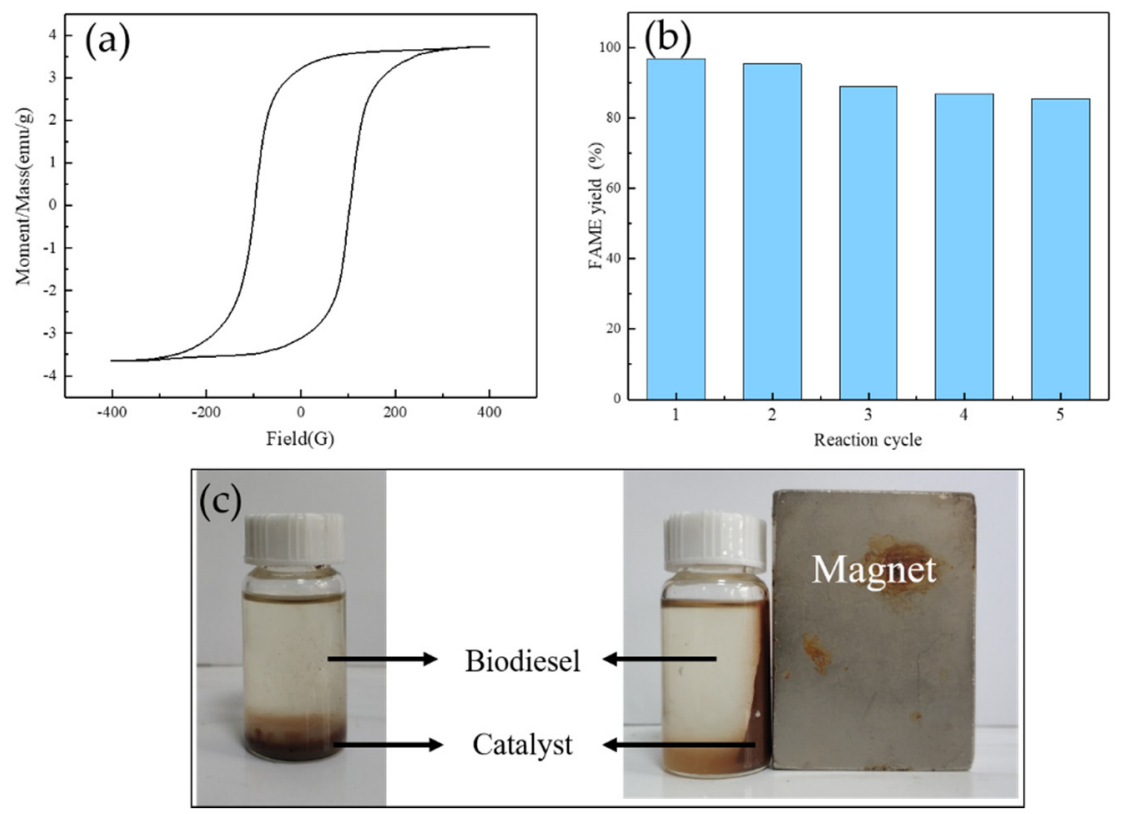

Figure 9. (a) VSM analysis of Ca80Fe20; (b) Reusability analysis of Ca80Fe20; (c) Photograph of Ca80Fe20 attracted by magnet in biodiesel.

\subsection{Response Surface Methodology (RSM) Optimization}

In this work, the data of the experimental and predicted FAME conversion were analyzed in the Box-Behnken model of the response surface system (four-factors, three-levels), as shown in Table 3 . By analyzing the data in Table 3, the regression equation for the FAME conversion (\%) was obtained from the equation as:

$$
\begin{gathered}
\mathrm{R}_{1}=71.34+14.82 \mathrm{~A}+ \\
7.23 \mathrm{~B}+6.63 \mathrm{C}+16.95 \mathrm{D}-4.90 \mathrm{AB}-5.78 \mathrm{AC}+12.45 \mathrm{AD}-1.32 \mathrm{BC}+8.93 \mathrm{BD} \\
+8.39 \mathrm{CD}-13.06 \mathrm{~A}^{2}-4.63 \mathrm{~B}^{2}-9.28 \mathrm{C}^{2}-15.43 \mathrm{D}^{2}
\end{gathered}
$$


Table 3. Design and results of the response surface analysis.

\begin{tabular}{|c|c|c|c|c|c|c|}
\hline Run & $\mathrm{A}\left({ }^{\circ} \mathrm{C}\right)$ & B(h) & C (wt.\%) & $\mathrm{D}(\mathrm{mol} / \mathrm{mol})$ & F (\%) & G (\%) \\
\hline 1 & 60.00 & 1.00 & 9.00 & 3.00 & 36.80 & 36.04 \\
\hline 2 & 70.00 & 1.00 & 9.00 & 9.00 & 67.92 & 66.15 \\
\hline 3 & 60.00 & 1.00 & 9.00 & 15.00 & 51.80 & 52.08 \\
\hline 4 & 60.00 & 3.00 & 5.00 & 9.00 & 65.75 & 59.35 \\
\hline 5 & 60.00 & 2.00 & 13.00 & 15.00 & 78.88 & 78.61 \\
\hline 6 & 60.00 & 3.00 & 9.00 & 3.00 & 35.00 & 32.63 \\
\hline 7 & 60.00 & 3.00 & 13.00 & 9.00 & 72.89 & 69.98 \\
\hline 8 & 50.00 & 2.00 & 9.00 & 3.00 & 23.71 & 23.53 \\
\hline 9 & 70.00 & 3.00 & 9.00 & 9.00 & 62.76 & 70.81 \\
\hline 10 & 60.00 & 3.00 & 9.00 & 15.00 & 85.74 & 84.41 \\
\hline 11 & 60.00 & 1.00 & 13.00 & 9.00 & 52.86 & 58.16 \\
\hline 12 & 50.00 & 3.00 & 9.00 & 9.00 & 46.01 & 50.96 \\
\hline 13 & 50.00 & 2.00 & 13.00 & 9.00 & 41.79 & 46.60 \\
\hline 14 & 60.00 & 2.00 & 9.00 & 9.00 & 72.45 & 71.34 \\
\hline 15 & 60.00 & 2.00 & 13.00 & 3.00 & 32.23 & 27.93 \\
\hline 16 & 60.00 & 2.00 & 9.00 & 9.00 & 70.14 & 71.34 \\
\hline 17 & 50.00 & 2.00 & 9.00 & 15.00 & 37.80 & 32.54 \\
\hline 18 & 60.00 & 2.00 & 9.00 & 9.00 & 75.45 & 71.34 \\
\hline 19 & 60.00 & 2.00 & 9.00 & 9.00 & 70.21 & 71.34 \\
\hline 20 & 50.00 & 2.00 & 5.00 & 9.00 & 21.22 & 21.77 \\
\hline 21 & 60.00 & 2.00 & 9.00 & 9.00 & 68.45 & 71.34 \\
\hline 22 & 70.00 & 2.00 & 13.00 & 9.00 & 67.32 & 64.68 \\
\hline 23 & 70.00 & 2.00 & 9.00 & 15.00 & 87.99 & 87.08 \\
\hline 24 & 60.00 & 2.00 & 5.00 & 3.00 & 27.98 & 31.44 \\
\hline 25 & 50.00 & 1.00 & 9.00 & 9.00 & 31.57 & 26.70 \\
\hline 26 & 60.00 & 1.00 & 5.00 & 9.00 & 40.44 & 42.25 \\
\hline 27 & 70.00 & 2.00 & 5.00 & 9.00 & 69.88 & 62.97 \\
\hline 28 & 60.00 & 2.00 & 5.00 & 15.00 & 41.08 & 48.57 \\
\hline 29 & 70.00 & 2.00 & 9.00 & 3.00 & 24.12 & 28.28 \\
\hline
\end{tabular}

The analysis of variance (ANOVA) in Table 4 lists the probability value ( $p$-value) of the significance and the F-value. The value of " $p$-value Prob. > F", less than 0.0100 , indicates that the model terms are extremely significant [38]. From the ANOVA, the $p$-value for the FAME conversion of the transesterification model was $<0.0001$, which indicates that the model is extremely significant. $\mathrm{D}$ (the molar ratio of methanol to oil) shows, at 3449.52, a higher sequential sum of squares than the reaction temperature (2636.96), reaction time (627.04) and catalyst dosage (528.09), and hence the molar ratio of methanol to oil proves to be the dominating factor [39]. The values of $R^{2}$ and the adj- $R^{2}$ for the FAME conversion of transesterification are 0.9615 and 0.9229 respectively. Thus, the regression equation of this model has a good adaptability and reliability.

The prediction of the optimal transesterification conditions was done using the point prediction function in Design Expert 8.0.6, with a high conversion of $96.20 \%$ at optimum conditions of $15: 1 \mathrm{M}$ ratio, $3 \mathrm{~h}$ of reaction time, $11.02 \mathrm{wt} . \%$ of catalyst dosage and $67.46^{\circ} \mathrm{C}$ of reaction temperature respectively. According to the actual conditions, the transesterification conditions were changed appropriately. Repeated experiments showed that the actual FAME conversion of $96.02 \%$ was obtained. Hence, the results were comparable with the prediction, and the regression model can be used to optimize the transesterification parameters. 
Table 4. Analysis of variance for the regression equation.

\begin{tabular}{|c|c|c|c|c|c|c|}
\hline Source & $\begin{array}{l}\text { Sum of } \\
\text { Squares }\end{array}$ & df & $\begin{array}{l}\text { Mean } \\
\text { Square }\end{array}$ & F Value & $p$-Value Prob $>$ F & \\
\hline Model & $11,091.53$ & 14 & 792.25 & 24.95 & $<0.0001$ & significant \\
\hline $\mathrm{A}$ & 2636.96 & 1 & 2636.96 & 83.05 & $<0.0001$ & \\
\hline B & 627.04 & 1 & 627.04 & 19.75 & 0.0006 & \\
\hline $\mathrm{C}$ & 528.09 & 1 & 528.09 & 16.63 & 0.0011 & \\
\hline $\mathrm{D}$ & 3449.52 & 1 & 3449.52 & 108.64 & $<0.0001$ & \\
\hline $\mathrm{AB}$ & 96.07 & 1 & 96.07 & 3.03 & 0.1039 & \\
\hline $\mathrm{AC}$ & 133.70 & 1 & 133.70 & 4.21 & 0.0594 & \\
\hline $\mathrm{AD}$ & 619.53 & 1 & 619.53 & 19.51 & 0.0006 & \\
\hline $\mathrm{BC}$ & 6.97 & 1 & 6.97 & 0.22 & 0.6467 & \\
\hline $\mathrm{BD}$ & 319.27 & 1 & 319.27 & 10.05 & 0.0068 & \\
\hline $\mathrm{CD}$ & 281.50 & 1 & 281.50 & 8.87 & 0.0100 & \\
\hline$A^{2}$ & 1105.79 & 1 & 1105.79 & 34.83 & $<0.0001$ & \\
\hline $\mathrm{B}^{2}$ & 138.86 & 1 & 138.86 & 4.37 & 0.0552 & \\
\hline$C^{2}$ & 558.62 & 1 & 558.62 & 17.59 & 0.0009 & \\
\hline $\mathrm{D}^{2}$ & 1543.61 & 1 & 1543.61 & 48.61 & $<0.0001$ & \\
\hline Residual & 444.54 & 14 & 31.75 & & & \\
\hline Lack of Fit & 415.38 & 10 & 41.54 & 5.70 & 0.0541 & not significant \\
\hline Pure Error & 29.16 & 4 & 7.29 & & & \\
\hline Cor Total & $11,536.06$ & 28 & & & & \\
\hline
\end{tabular}

\section{Conclusions}

In the present work, an easy one-step hydrothermal synthesis of a magnetic catalyst, $\gamma-\mathrm{Fe}_{2} \mathrm{O}_{3}$ stabilized $\mathrm{CaO}$ microspheres featuring multi-shelled morphologies, was successfully synthesized, characterized and used to produce biodiesel from palm oil. It demonstrated that the preparation method for $\gamma-\mathrm{Fe}_{2} \mathrm{O}_{3}$ incorporation plays a major role. The Ca80Fe20 catalyst showed the best catalytic performance and verified that $\gamma-\mathrm{Fe}_{2} \mathrm{O}_{3}$ addition is essential for the creation of active sites and the stability of the structure. Following a series of experiments over Ca80Fe20, the optimum transesterification conditions were reaction conditions of $2 \mathrm{~h}$, a methanol to oil ratio of $12: 1,65^{\circ} \mathrm{C}$ and $11 \mathrm{wt} . \%$ of catalyst dosage to produce $96.12 \%$ of FAME. The multi-shelled microspheres exhibited a large surface area which provides more accessible active sites for transesterification. The catalyst has been recycled and reused up to five runs with $>85 \%$ of FAME conversion. The existence of $\gamma-\mathrm{Fe}_{2} \mathrm{O}_{3}$ caused a positive influence on the catalyst reusability and stability. The RSM predicted that the highest FAME conversion was $96.20 \%$ under reaction conditions of $3 \mathrm{~h}$, a methanol to oil ratio of $15: 1,67.46^{\circ} \mathrm{C}$ and $11.02 \mathrm{wt} . \%$ of catalyst dosage, which was in good agreement with the experimental data. In conclusion, the magnetic multi-shelled hollow catalyst $\left(\gamma-\mathrm{Fe}_{2} \mathrm{O}_{3} / \mathrm{CaO}\right)$ can be an efficient, economical and potential catalyst for green biodiesel production from palm oil. 
Author Contributions: The conceptualization of this journal article is from L.Z., J.Y. and H.C.; the writing-original draft was prepared by J.L.; W.Y., Z.R. and Z.Y. helped with the editing and supervision. L.Z. performed and developed the experiment, learned Design Expert software, analyzed the data and wrote the paper. All authors have read and agreed to the published version of the manuscript.

Funding: This research was funded by the National Key Research and Development Program of China (No. 2018YFB1403302).

Conflicts of Interest: The authors declare no conflict of interest.

\section{References}

1. Yin, Z.; Zhu, L.; Li, S.; Hu, T.; Chu, R.; Mo, F.; Hu, D.; Liu, C.; Li, B. A comprehensive review on cultivation and harvesting of microalgae for biodiesel production: Environmental pollution control and future directions. Bioresour. Technol. 2020, 301, 122804. [CrossRef] [PubMed]

2. Sai, B.A.V.S.L.; Subramaniapillai, N.; Khadhar Mohamed, M.S.B.; Narayanan, A. Optimization of continuous biodiesel production from rubber seed oil (RSO) using calcined eggshells as heterogeneous catalyst. J. Environ. Chem. Eng. 2020, 8, 103603.

3. Roschat, W.; Phewphong, S.; Thangthong, A.; Moonsin, P.; Yoosuk, B.; Kaewpuang, T.; Promarak, V. Catalytic performance enhancement of $\mathrm{CaO}$ by hydration-dehydration process for biodiesel production at room temperature. Energy Convers. Manag. 2018, 165, 1-7. [CrossRef]

4. Mallah, T.A.; Sahito, A.R. Optimization of castor and neem biodiesel blends and development of empirical models to predicts its characteristics. Fuel 2020, 262, 116341. [CrossRef]

5. Fazal, M.A.; Rubaiee, S.; Al-Zahrani, A. Overview of the interactions between automotive materials and biodiesel obtained from different feedstocks. Fuel Process. Technol. 2019, 196, 106178. [CrossRef]

6. Lee, A.F.; Bennett, J.A.; Manayil, J.C.; Wilson, K. Heterogeneous catalysis for sustainable biodiesel production via esterification and transesterification. Chem. Soc. Rev. 2014, 43, 7887-7916. [CrossRef]

7. Silitonga, A.S.; Shamsuddin, A.H.; Mahlia, T.M.I.; Milano, J.; Kusumo, F.; Siswantoro, J.; Dharma, S.; Sebayang, A.H.; Masjuki, H.H.; Ong, H.C. Biodiesel synthesis from Ceiba pentandra oil by microwave irradiation-assisted transesterification: ELM modeling and optimization. Renew. Energy 2020, 146, 1278-1291. [CrossRef]

8. Anastopoulos, G.; Zannikou, Y.; Stournas, S.; Kalligeros, S. Transesterification of Vegetable Oils with Ethanol and Characterization of the Key Fuel Properties of Ethyl Esters. Energies 2009, 2, 362-376. [CrossRef]

9. Gad, M.S.; Jayaraj, S. A comparative study on the effect of nano-additives on the performance and emissions of a diesel engine run on Jatropha biodiesel. Fuel 2020, 267, 117168. [CrossRef]

10. Dahdah, E.; Estephane, J.; Haydar, R.; Youssef, Y.; El Khoury, B.; Gennequin, C.; Aboukaïs, A.; Abi-Aad, E.; Aouad, S. Biodiesel production from refined sunflower oil over $\mathrm{Ca}-\mathrm{Mg}-\mathrm{Al}$ catalysts: Effect of the composition and the thermal treatment. Renew. Energy 2020, 146, 1242-1248. [CrossRef]

11. Mazaheri, H.; Ong, H.C.; Masjuki, H.H.; Amini, Z.; Harrison, M.D.; Wang, C.; Kusumo, F.; Alwi, A. Rice bran oil based biodiesel production using calcium oxide catalyst derived from Chicoreus brunneus shell. Energy 2018, 144, 10-19. [CrossRef]

12. Sirisomboonchai, S.; Abuduwayiti, M.; Guan, G.; Samart, C.; Abliz, S.; Hao, X.; Kusakabe, K.; Abudula, A. Biodiesel production from waste cooking oil using calcined scallop shell as catalyst. Energy Convers. Manag. 2015, 95, 242-247. [CrossRef]

13. Veena Singh, L.B.B.S. Biodiesel production using a novel heterogeneous catalyst, magnesium zirconate $\left(\mathrm{Mg}_{2} \mathrm{Zr}_{5} \mathrm{O}_{12}\right)$ : Process optimization through response surface methodology RSM. Energy Convers. Manag. 2018, 174, 198-207. [CrossRef]

14. Marinković, D.M.; Stanković, M.V.; Veličković, A.V.; Avramović, J.M.; Miladinović, M.R.; Stamenković, O.O.; Veljković, V.B.; Jovanović, D.M. Calcium oxide as a promising heterogeneous catalyst for biodiesel production: Current state and perspectives. Renew. Sustain. Energy Rev. 2016, 56, 1387-1408. [CrossRef]

15. Banković Ilić, I.B.; Miladinović, M.R.; Stamenković, O.S.; Veljković, V.B. Application of nano CaO-based catalysts in biodiesel synthesis. Renew. Sustain. Energy Rev. 2017, 72, 746-760. [CrossRef]

16. Risso, R.; Ferraz, P.; Meireles, S.; Fonseca, I.; Vital, J. Highly active Cao catalysts from waste shells of egg, oyster and clam for biodiesel production. Appl. Catal. A Gen. 2018, 567, 56-64. [CrossRef] 
17. Toledo Arana, J.; Torres, J.J.; Acevedo, D.F.; Illanes, C.O.; Ochoa, N.A.; Pagliero, C.L. One-Step Synthesis of CaO-ZnO Efficient Catalyst for Biodiesel Production. Int. J. Chem. Eng. 2019, 2019, 1-7. [CrossRef]

18. Chen, G.; Shan, R.; Yan, B.; Shi, J.; Li, S.; Liu, C. Remarkably enhancing the biodiesel yield from palm oil upon abalone shell-derived CaO catalysts treated by ethanol. Fuel Process. Technol. 2016, 143, 110-117. [CrossRef]

19. Liu, Y.; Zhang, P.; Fan, M.; Jiang, P. Biodiesel production from soybean oil catalyzed by magnetic nanoparticle $\mathrm{MgFe}_{2} \mathrm{O}_{4} @ \mathrm{CaO}$. Fuel 2016, 164, 314-321. [CrossRef]

20. Ezzah-Mahmudah, S.; Lokman, I.M.; Saiman, M.I.; Taufiq-Yap, Y.H. Synthesis and characterization of $\mathrm{Fe}_{2} \mathrm{O}_{3} / \mathrm{CaO}$ derived from Anadara Granosa for methyl ester production. Energy Convers. Manag. 2016, 126, 124-131. [CrossRef]

21. Shi, M.; Zhang, P.; Fan, M.; Jiang, P.; Dong, Y. Influence of crystal of $\mathrm{Fe}_{2} \mathrm{O}_{3}$ in magnetism and activity of nanoparticle $\mathrm{CaO} @ \mathrm{Fe}_{2} \mathrm{O}_{3}$ for biodiesel production. Fuel 2017, 197, 343-347. [CrossRef]

22. Wan, D.; Yan, C.; Zhang, Q. Facile and Rapid Synthesis of Hollow Magnetic Mesoporous Polydopamine Nanoflowers with Tunable Pore Structures for Lipase Immobilization: Green Production of Biodiesel. Ind. Eng. Chem. Res. 2019, 58, 16358-16369. [CrossRef]

23. Xie, W.; Wang, H. Immobilized polymeric sulfonated ionic liquid on core-shell structured $\mathrm{Fe}_{3} \mathrm{O}_{4} / \mathrm{SiO}_{2}$ composites: A magnetically recyclable catalyst for simultaneous transesterification and esterifications of low-cost oils to biodiesel. Renew. Energy 2020, 145, 1709-1719. [CrossRef]

24. Feng, J.; Guo, H.; Wang, S.; Zhao, Y.; Ma, X. Fabrication of multi-shelled hollow Mg-modified $\mathrm{CaCO}_{3}$ microspheres and their improved $\mathrm{CO}_{2}$ adsorption performance. Chem. Eng. J. 2017, 321, 401-411. [CrossRef]

25. Loy, A.C.M.; Quitain, A.T.; Lam, M.K.; Yusup, S.; Sasaki, M.; Kida, T. Development of high microwave-absorptive bifunctional graphene oxide-based catalyst for biodiesel production. Energy Convers. Manag. 2019, 180,1013-1025. [CrossRef]

26. Naeem, M.A.; Armutlulu, A.; Imtiaz, Q.; Donat, F.; Schaublin, R.; Kierzkowska, A.; Muller, C.R. Optimization of the structural characteristics of $\mathrm{CaO}$ and its effective stabilization yield high-capacity $\mathrm{CO}_{2}$ sorbents. Nat. Commun. 2018, 9, 2408. [CrossRef]

27. Xue, B.; Luo, J.; Zhang, F.; Fang, Z. Biodiesel production from soybean and Jatropha oils by magnetic $\mathrm{CaFe}_{2} \mathrm{O}_{4}-\mathrm{Ca}_{2} \mathrm{Fe}_{2} \mathrm{O}_{5}$-based catalyst. Energy 2014, 68, 584-591. [CrossRef]

28. Sano, N.; Yamada, K.; Tsunauchi, S.; Tamon, H. A novel solid base catalyst for transesterification of triglycerides toward biodiesel production: Carbon nanohorn dispersed with calcium ferrite. Chem. Eng. J. 2017, 307, 135-142. [CrossRef]

29. Maneerung, T.; Kawi, S.; Dai, Y.; Wang, C. Sustainable biodiesel production via transesterification of waste cooking oil by using $\mathrm{CaO}$ catalysts prepared from chicken manure. Energy Convers. Manag. 2016, 123, 487-497. [CrossRef]

30. Ramos Guivar, J.A.; Sanches, E.A.; Bruns, F.; Sadrollahi, E.; Morales, M.A.; López, E.O.; Litterst, F.J. Vacancy ordered $\gamma-\mathrm{Fe}_{2} \mathrm{O}_{3}$ nanoparticles functionalized with nanohydroxyapatite: XRD, FTIR, TEM, XPS and Mössbauer studies. Appl. Surf. Sci. 2016, 389, 721-734. [CrossRef]

31. Khan, I.U.; Yan, Z.; Chen, J. Optimization, Transesterification and Analytical Study of Rhus typhina Non-Edible Seed Oil as Biodiesel Production. Energies 2019, 12, 4290. [CrossRef]

32. Girdhar Joshi, D.S.R.B.; Kumar, S. Transesterification of Jatropha and Karanja oils by using waste egg shell derived calcium based mixed metal oxides. Energy Convers. Manag. 2015, 96, 258-267. [CrossRef]

33. Abdollahi Asl, M.; Tahvildari, K.; Bigdeli, T. Eco-friendly synthesis of biodiesel from WCO by using electrolysis technique with graphite electrodes. Fuel 2020, 270, 117582. [CrossRef]

34. Teo, S.H.; Islam, A.; Chan, E.S.; Thomas Choong, S.Y.; Alharthi, N.H.; Taufiq-Yap, Y.H.; Awual, M.R. Efficient biodiesel production from Jatropha curcus using $\mathrm{CaSO}_{4} / \mathrm{Fe}_{2} \mathrm{O}_{3}-\mathrm{SiO}_{2}$ core-shell magnetic nanoparticles. J. Clean. Prod. 2019, 208, 816-826. [CrossRef]

35. Shi, Y.; Liang, X. Novel carbon microtube based solid acid from pampas grass stick for biodiesel synthesis from waste oils. J Saudi Chem. Soc. 2019, 23, 515-524. [CrossRef]

36. Ambat, I.; Srivastava, V.; Haapaniemi, E.; Sillanpää, M. Nano-magnetic potassium impregnated ceria as catalyst for the biodiesel production. Renew. Energy 2019, 139, 1428-1436. [CrossRef]

37. Du, L.; Li, Z.; Ding, S.; Chen, C.; Qu, S.; Yi, W.; Lu, J.; Ding, J. Synthesis and characterization of carbon-based $\mathrm{MgO}$ catalysts for biodiesel production from castor oil. Fuel 2019, 258, 116122. [CrossRef] 
38. Li, X.; Lei, T.; Wang, Z.; Li, X.; Wen, M.; Yang, M.; Chen, G.; He, X.; Xu, H.; Guan, Q.; et al. Catalytic pyrolysis of corn straw with magnetic solid acid catalyst to prepare levulinic acid by response surface methodology. Ind. Crop. Prod. 2018, 116, 73-80. [CrossRef]

39. Da Conceição, L.R.V.; Carneiro, L.M.; Rivaldi, J.D.; de Castro, H.F. Solid acid as catalyst for biodiesel production via simultaneous esterification and transesterification of macaw palm oil. Ind. Crop. Prod. 2016, 89, 416-424. [CrossRef]

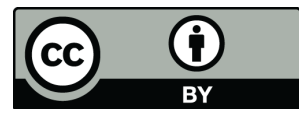

(C) 2020 by the authors. Licensee MDPI, Basel, Switzerland. This article is an open access article distributed under the terms and conditions of the Creative Commons Attribution (CC BY) license (http://creativecommons.org/licenses/by/4.0/). 